\title{
Impact of consumer profiles and forecast accuracy on day-ahead scheduling of household appliances
}

\author{
Chloe Lucas \\ Univ. Grenoble Alpes, INES \\ CEA LITEN, Smart Grid Laboratory \\ F-73375 Le Bourget-du-Lac, France \\ chloe.lucas@cea.fr
}

\author{
Mouloud Guemri \\ Univ. Grenoble Alpes, INES \\ CEA LITEN, Smart Grid Laboratory \\ F-73375 Le Bourget-du-Lac, France \\ mouloud.guemri@cea.fr
}

\author{
Quoc Tuan Tran \\ Univ. Grenoble Alpes, INES \\ CEA LITEN, Smart Grid Laboratory \\ F-73375 Le Bourget-du-Lac, France \\ quoctuan.tran@cea.fr
}

\begin{abstract}
Due to the increasing profitability of photovoltaic systems, the penetration of decentralized domestic photovoltaic energy sources is growing. Contrarily to conventional energy sources, photovoltaic systems cannot be scheduled to meet the consumption. This prompts the need to shift the energy consumption towards times with high photovoltaic production. Indeed, local consumption of the produced energy allows the prosumer to increase the profitability of its photovoltaic system and decreases the impact of high photovoltaic penetration on the distribution grid. To this end, energy management methods are investigated. However, the benefits of the methods are inherently dependent on the study case. This paper presents a sensitivity analysis based on a demand response method, investigating its dependency with the prosumer load profile and with the production forecast accuracy. The demand response method introduces flexibility in the time-of-use of electricity consuming devices in order to increase the profitability of photovoltaic systems, but also to reduce the peak power exchanged with the distribution grid.
\end{abstract}

Keywords—photovoltaic, demand response, self-consumption, optimization, forecast, genetic algorithm

\section{INTRODUCTION}

In France, grid parity is about to be reached, making photovoltaic (PV) systems profitable without subsidies [1], [2]. The profitability of PV systems is likely to prompt the development of decentralized residential PV. A high penetration of distributed generators (DG) on low-voltage grids triggers the need either to enhance the grid infrastructure or to occasionally curtail the renewable production. Authors in [3] showed how demand response (DR) can help control voltage in distribution grids with high DG penetration, by decreasing the power exchanged with the grid. In this way, demand response can reduce the need for grid reinforcement in spite of a high PV penetration rate. Another benefit of DR is for a prosumer to increase the profitability of its PV system. In a situation where the selling price of $\mathrm{PV}$ power is lower than electricity retail price, it is more lucrative for the prosumer to shift his energy consumption in order to consume its own electricity, as illustrated on Fig. 1.

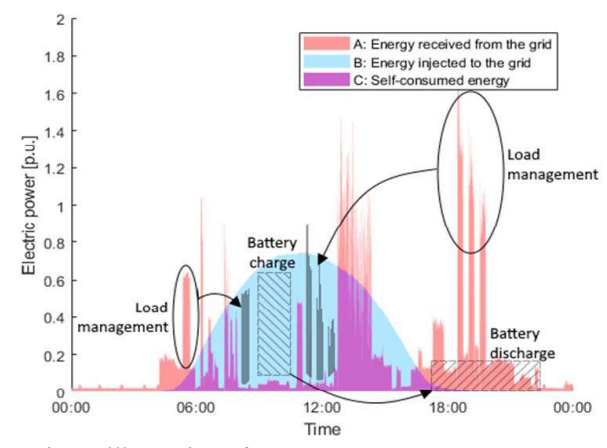

Fig. 1: illustration of an energy management strategy.
In a context of increasing penetration of decentralized PV systems, energy management methods are increasingly investigated. Authors in [4] reviewed scientific literature on self-consumption (SC) and found that two methods to increase $\mathrm{SC}$ are mainly used: energy storage management and active load shifting. According to [5], information technologies enable the demand to become more flexible, "thanks to the ability of real time sensing, controlling and scheduling the power usage, and the introduction of mobile loads and local storage". Similar studies in [6]-[10] present various methods to take advantage of this flexibility and increase the simultaneity of demand and production.

Depending on the aim of the energy management strategy, three indicators can be used to quantify the results: the selfconsumption rate $\mathrm{SC}_{\%}$, the self-production rate $\mathrm{SP}_{\%}$ and the peak exchanged power $\mathrm{P}_{\max }$. When striving for a bigger amount of energy consumed locally (surface $\mathrm{C}$ on Fig. 1), $\mathrm{SC}_{\%}$ and $\mathrm{SP}_{\%}$ are the main metrics. $\mathrm{SC}_{\%}$ represents the locally consumed share of the produced energy, and $\mathrm{SP}_{\%}$ represents the locally produced share of the consumed energy. These two indicators are defined in Eq. (1) and (2) based on Fig. 1. When aiming at reducing the impact of a prosumer on the distribution grid, the peak exchanged power can be used as an indicator.

$$
\begin{aligned}
& S C_{\%}=\frac{C}{B+C} \\
& S P_{\%}=\frac{C}{A+C}
\end{aligned}
$$

However, the improvement brought by these energy management strategies is inherently dependent on the study case. Authors in [4] point out significant variations in the results of scientific research about the use of storage and demand response to increase the amount of self-consumed energy. They explain that "many influential factors differ between the studies, e.g. climate, building characteristics, load types, PV system sizes, etc". In addition, for energy management methods based on day-ahead PV production forecasts, the accuracy of the forecast can influence the results of the study.

This paper investigates how the benefits brought by a demand response method depend on variations in prosumers load profiles and production forecast accuracy. An demand response method based on a genetic algorithm is implemented to schedule day-ahead programmable loads in a household. The genetic algorithm was chosen because of its ease of implementation and its ability to look rapidly through the solution space. The method considers that electricity prosumers have the capacity to shift part of their load by scheduling programmable appliances to increase the consumption of self-produced energy. The potential of a prosumer to improve its consumption pattern depends on the 
available PV power and on the programmable share of the consumption. Two types of weather forecast are used in the paper. In the reference case, called 'ideal forecast', it is assumed that the PV production of the next day is known dayahead with complete accuracy. In the second case, called 'realistic forecast', a day-ahead PV production forecast is provided by a third party short term PV forecasting service.

This paper is organized as follows: Part II describes the approach used to solve the optimal scheduling problem under constraints. Part III describes the data used in the different study cases. Part IV investigates the impact of the prosumer profile on the results of the algorithm. Part V addresses the issue of realistic forecast and its impact on the obtained results. Finally, Part VI discusses the results and gives perspectives for future work.

\section{APPROACH USED}

\section{A. Problem definition}

The consumption profile $\mathrm{P}_{\text {cons }}$ of an household is composed of two parts: a baseload profile $\mathrm{P}_{\text {base }}$ that cannot be controlled, and a set of shiftable loads that can be scheduled to start at predefined times. For this purpose, the household is equipped with a set $A$ of programmable appliances, each appliance $a$ being used to satisfy a set $N(a)$ of day-to-day needs. Each need $n$ in $N(a)$ has a predefined consumption profile $P_{a, n}$, a duration $d_{n}$, and a set $O(n)$ of occurrences in the following day. During the day-ahead optimization phase, a genetic algorithm schedules each occurrence of a need to start with a delay $\mu_{0}$. This is formalized in (3).

$$
P_{\text {cons }}(t)=P_{\text {base }}(t)+\sum_{\mathrm{a} \in A} \sum_{\mathrm{n} \in N(\mathrm{a})} \sum_{o \in O(n)} P_{a, n}\left(t-\mu_{o}\right)
$$

The production source examined in this paper is a PV system with a production curve $\mathrm{P}_{\mathrm{PV}}$. Thus, the power exchanged between the household and the electricity grid is given in (4).

$$
P_{\text {exch }}(t)=P_{\text {cons }}(t)-P_{P V}(t)
$$

\section{B. Constraints of the problem}

In order to simulate the operation of an actual PV system, following constraints are added to the problem: the consumed power cannot exceed the power $\mathrm{P}_{\text {sub }}$ subscribed from the DSO (5), and two needs requiring the same appliance cannot satisfied simultaneously (6). In (6), $d_{n}$ is the duration of the need associated with the occurrence $\mathrm{o}_{i}$ or $\mathrm{o}_{\mathrm{j}}$, that has the earliest starting time and $\left|\mu_{\mathrm{oi}}-\mu_{\mathrm{oj}}\right|$ is the time difference between two starts of appliance a.

$$
\begin{gathered}
\forall t, P_{\text {cons }}(t) \leq P_{\text {sub }}(t) \\
\forall a \in A, \forall o_{i}, o_{j} \in \bigcup_{n \in N(a)} O(n),\left|\mu_{o_{i}}-\mu_{o_{j}}\right|>d_{n}
\end{gathered}
$$

\section{Objective functions and evaluation of the results}

The genetic algorithm takes a population of 250 individuals, each individual being the set of delay times for all occurrences of every need requiring one of the programmable appliance in the household in the following day. This population evolves over generations depending on the ability of its individuals to meet a chosen optimization objective. The optimization process targets a single objective among maximizing $\mathrm{SC}_{\%}$, maximizing $\mathrm{SP}_{\%}$ or minimizing the peak exchanged power $\mathrm{P}_{\max }$. Mathematical formulation of the three indicators are given in Eq. (7)-(9).

$$
\begin{gathered}
S C_{\%}=\frac{\int_{\text {day }} \min \left(P_{\text {cons }}(t), P_{P V}(t)\right) d t}{\int_{\text {day }} P_{P V}(t) d t} \\
S P_{\%}=\frac{\int_{\text {day }} \min \left(P_{\text {cons }}(t), P_{P V}(t)\right) d t}{\int_{\text {day }} P_{\text {cons }}(t) d t} \\
P_{\text {max }}=\max _{\mathrm{t}}\left(P_{\text {cons }}(t)-P_{P V}(t)\right)
\end{gathered}
$$

Eq. (10)-(12) indicate the percentage gain of the selfconsumption rate, the self-production rate and the maximal peak power, with $\mathrm{X}_{\mathrm{ini}}$ and $\mathrm{X}_{\mathrm{opt}}$ the values of indicator $\mathrm{X}$ respectively before and after optimization.

$$
\begin{gathered}
g_{S C}=\frac{S C_{\%, \text { opt }}-S C_{\%, \text { ini }}}{S C_{\%, \text { ini }}} \cdot 100 \\
g_{S P}=\frac{S P_{\%, \text { opt }}-S P_{\%, \text { ini }}}{S P_{\%, \text { ini }}} \cdot 100 \\
g_{P}=\frac{P_{\text {max }, \text { ini }}-P_{\text {max }, \text { opt }}}{P_{\text {max }, \text { ini }}} \cdot 100 \\
\text { III. AVAILABLE DATA }
\end{gathered}
$$

\section{A. Consumption profiles}

The consumption profiles of the studied households are extracted from the Load Profile Generator (LPG) [11]. LPG generates a consumption pattern for a chosen household template using a behavior based model. Three household templates provided by LPG have been used in this paper:

- CHR05: 5 person family, both parents work outside home

- CHR35: single person, works outside home

- CHR04: couple, one works outside home, one at home

Table 1 provides information on the generated consumption patterns, such as the yearly consumption, the programmable appliances available (dishwasher DW, washing machine WM and dryer DR), the mean use of these appliances per week, and their share in the total consumption. It can be observed from this data that the consumption patterns vary among the three household templates. CHR05 has the highest consumption, the highest share of programmable appliances in the consumption and the most frequent use of the appliances. On the other hand, CHR35 has the lowest share and the less frequent use of programmable appliances, as well as the lowest overall consumption. CHR04 has an intermediate consumption and use of the programmable appliances. The demand response method presented in Part II will be able to control $32.4 \%$ of CHR05 consumption, $7.5 \%$ of CHR35 consumption and $12.1 \%$ of CHR0 4 consumption.

Table 1: consumption data for three household templates

\begin{tabular}{lccc}
\cline { 2 - 4 } & \multicolumn{3}{c}{ Household template } \\
& CHR05 & CHR35 & CHR04 \\
\hline Yearly consumption [kWh] & 5419 & 1828 & 3178 \\
$\begin{array}{l}\text { Programmable appliances } \\
\begin{array}{l}\text { Mean use of appliances } \\
{[\text { times/day] }}\end{array}\end{array}$ & 2.3 & 0.4 & 0.9 \\
$\begin{array}{l}\text { Share of prog. appliances in } \\
\text { consumption [\%] }\end{array}$ & 32.4 & 7.5 & 12.1 \\
\hline
\end{tabular}




\section{B. Production profiles}

The PV production forecast used in Part IV is generated by solving the single-diode model under irradiance data from the Copernicus Atmosphere Monitoring Service Information for the year 2015. The day-ahead optimization in Part IV is therefore based on an ideal forecast of the PV production. Three sizes of PV systems are considered: $1.1 \mathrm{kWp}, 2.2 \mathrm{kWp}$ and $4.4 \mathrm{kWp}$, respectively producing $3.2 \mathrm{MWh} /$ year, 6.3 MWh/year and 9.5 MWh/year.

To investigate the impact of $\mathrm{PV}$ production forecast accuracy on the result of the optimization method (Part V), the appliances are scheduled based on a realistic day ahead forecast of the PV production. This forecast is provided for an existing PV system by a third-party expert system combining artificial intelligence, statistical and physical models. The actual production of the PV system is monitored and used to evaluate indicators $\mathrm{SC}_{\%}, \mathrm{SP}_{\%}$ and $\mathrm{P}_{\max }$. The indicators are compared with those obtained from an 'ideal forecast' of the PV production. In this 'ideal forecast', measures of the production are used for both the day-ahead scheduling and the evaluation of the indicators.

\section{IMPACT OF CONSUMPTION PROFILE}

In this part, the genetic algorithm schedules appliances for nine prosumer profiles labeled $\mathrm{P} 1$ to $\mathrm{P} 9$, obtained by crossing the three consumption profiles with the three sizes of PV systems. The characteristics of the prosumer profiles are given in Table 2. The simulations run over one year, to take into account seasonal variations in consumption and production.

Table 2: Description of the simulated prosumers

\begin{tabular}{cccc}
\hline $\begin{array}{c}\text { Household } \\
\text { template }\end{array}$ & \multicolumn{3}{c}{ Peak power of the PV system [kWp] } \\
& $\mathbf{1 . 1}$ & $\mathbf{2 . 2}$ & 4.4 \\
\hline CHR05 & P1 & P2 & P3 \\
CHR35 & P4 & P5 & P6 \\
CHR04 & P7 & P8 & P9 \\
\hline
\end{tabular}

\section{A. Results}

Table 3 presents the results of the study: for each profile, the algorithm was applied three times, for the three objective functions described in Part II.C. The yearly values of $\mathrm{SC}_{\%}$, $\mathrm{SP}_{\%}$ and $\mathrm{P}_{\max }$ are given before and after applying the scheduling algorithm, and the gains $\mathrm{g}_{\mathrm{sc}}, \mathrm{g}_{\mathrm{sp}}$ and $\mathrm{g}_{\mathrm{p}}$ are calculated based on Eq. (10)-(12).

Table 3: Yearly self-consumption rate, self-production rate and maximal peak power before and after optimization for each profile

\begin{tabular}{cccccccccc}
\hline \multirow{2}{*}{ Profile } & \multicolumn{2}{c}{ SC $_{\%}$} & \multicolumn{2}{c}{ SP $_{\%}$} & \multicolumn{2}{c}{$\mathbf{P}_{\max }[\mathbf{k W}]$} & & & \\
& Ini & Opti & Ini & Opti & Ini & Opti & & $\mathbf{g}_{\text {sp }}$ & $\mathbf{g}_{\mathbf{p}}$ \\
\hline P1 & 50 & 68 & 15 & 20 & 7.9 & 6.2 & 36 & 33 & 22 \\
P2 & 37 & 56 & 22 & 32 & 7.6 & 6.1 & 51 & 45 & 20 \\
P3 & 27 & 42 & 31 & 49 & 7.6 & 6.0 & 56 & 58 & 21 \\
\hline P4 & 24 & 29 & 21 & 25 & 4.8 & 4.4 & 21 & 19 & 8 \\
P5 & 16 & 20 & 28 & 33 & 4.8 & 4.4 & 25 & 18 & 8 \\
P6 & 10 & 12 & 36 & 42 & 4.8 & 4.4 & 20 & 17 & 8 \\
\hline P7 & 51 & 57 & 25 & 28 & 5.9 & 5.4 & 12 & 12 & 8 \\
P8 & 40 & 44 & 38 & 43 & 5.3 & 4.7 & 10 & 13 & 11 \\
P9 & 27 & 30 & 53 & 58 & 5.1 & 4.2 & 11 & 9 & 18 \\
\hline
\end{tabular}

The three household templates chosen show different shares of energy consumed by programmable appliances in the total consumed energy (see Table 2). However, Fig. 2 shows no direct relationship between this share and the gains generated by the algorithm, defined in Eq. (10). Indeed, in its initial consumption pattern, household CHR04 already has a use of programmable appliances during the day time, as depicted on Fig. 3, while CHR05 and CHR35 have an important use of flexible appliances in the evening. Since CHR04 use of programmable appliances is initially already at hours with PV production, the demand method response brings little improvement to $\mathrm{SC}_{\%}, \mathrm{SP}_{\%}$ or $\mathrm{P}_{\max }$.

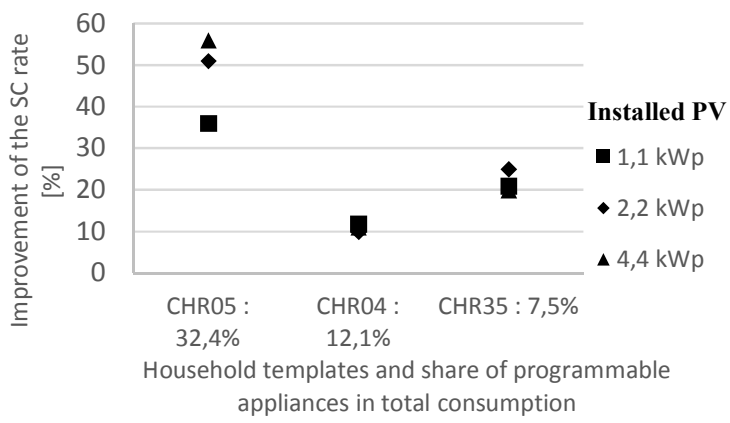

Fig. 2: Improvement of the self-consumption rate for each household
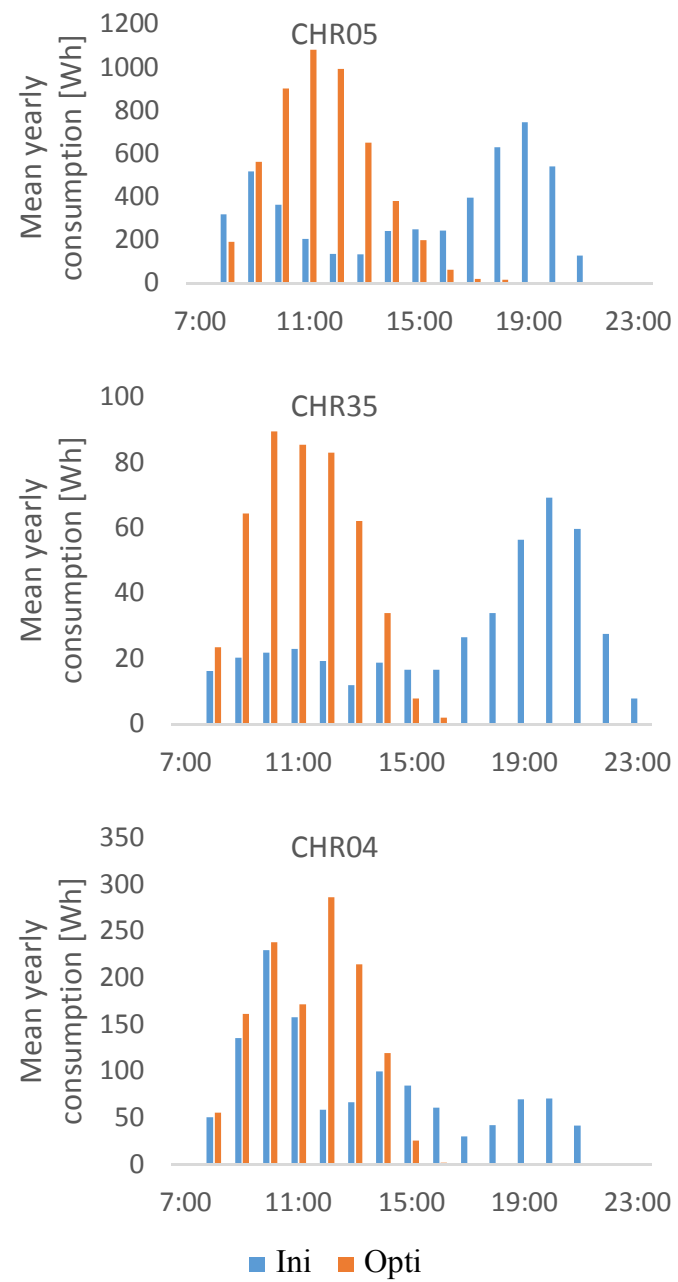

Fig. 3: Repartition of programmable appliances consumption through the day, before and after optimization 
The results in Table 3 also show that $\mathrm{SC}_{\%}$ and $\mathrm{SP}_{\%}$ vary significantly depending on the sizing of the PV system, while $\mathrm{P}_{\max }$ stays quite stable. Indeed, in the nine study cases, $\mathrm{P}_{\max }$ happens when withdrawing energy from the grid.

\section{B. Discussion}

The results in Table 3 show, for each prosumer profile, a positive impact of the scheduling for all three optimization objectives: applying the demand response method increases $\mathrm{SP}_{\%}$ and $\mathrm{SC}_{\%}$ and decreases $\mathrm{P}_{\max }$. The impact is most remarkable for profile P3. For this prosumer profile, $\mathrm{g}_{\mathrm{sc}}$ is worth $56 \%, \mathrm{~g}_{\mathrm{sp}}$ is worth $58 \%$ and $\mathrm{g}_{\mathrm{p}}$ is worth $21 \%$. By scheduling his appliances, this prosumer increases his amount of self-consumed energy by $647 \mathrm{kWh}$. In France, a prosumer similar to P3, with a $4.4 \mathrm{kWp}$ PV system and a $9 \mathrm{kVA}$ electricity subscription will sell its production surplus $6 \mathrm{ct} € / \mathrm{kWh}$ [13] and buy its electricity $14.69 \mathrm{ct} / \mathrm{kWh}$. Therefore, the $647 \mathrm{kWh}$ increase in its self-consumed energy will make a $56 €$ difference on its electricity bill each year. The decrease in the maximal power exchanged with the DSO could allow this prosumer to switch from a $9 \mathrm{kVA}$ to a $6 \mathrm{kVA}$ subscription, saving him $15 €$ /year [14].

However, the values of $g_{s c}, g_{s p}$ and $g_{p}$ in Table 3 also shows the difficulty of assessing the quality of an energy management method. When evaluating improvement brought by the method, we find important discrepancies depending on the the study case. Indeed, each prosumer has a different potential for shifting its consumption. This confirms the difficulty pointed out in [4] to distinguish a trend in the increase of self-consumption using demand response.

It is therefore advisable to apply a demand response method to different prosumer profiles when assessing its results. In this way, the potential of the method can be assessed under various conditions. Numerous parameters can vary among the prosumer profiles: the overall production and consumption, the consumption pattern without demand side management, the magnitude of the seasonal variations in demand and production, or the share of the consumption that can be shifted.

\section{IMPACT OF FORECAST QUALITY}

In the previous part, programmable appliances in several households where scheduled day-ahead, based on an ideal forecast of the production. In order to emulate this ideal forecast, the same measured irradiance data was used as dayahead forecast and as actual irradiance. However, an energy management system implemented in a real household would have to decide of the scheduling of appliances based on forecasts of the PV production. In this part, the results of the method based on an ideal forecast are compared to the results based on a realistic day-ahead forecast of the production, in order to assess the impact of forecast quality.

The PV production profiles used in this part come from a PV plant in the French Alps. A third party service provides a day-ahead forecast of the production, and the actual production is monitored. The data is scaled to simulate production from a $4.4 \mathrm{kWp}$ PV system. The forecast and measured productions are illustrated on Fig. 4 for a one week period. The scheduling method is applied for prosumer P3 as described in Part IV. In the first case, the genetic algorithm searches an optimal scheduling based on the day-ahead PV production forecast (realistic forecast) and in the second case based on the measured production (ideal forecast).

\section{A. Results}

Table 4 presents the daily $\mathrm{SC}_{\%}$ of prosumer P3 with the initial consumption pattern (without optimization of the demand) and with consumption patterns optimized based on realistic and ideal production forecasts. The percentage gain $\mathrm{g}_{\mathrm{sc}}$ is also calculated. Both optimized consumption patterns show an improvement compared with the initial case. For two days, $9^{\text {th }}$ and $10^{\text {th }}$ of February, the use of a realistic forecast decreases $\mathrm{SC} \%$ by more $10 \%$, and for the five others days the results are fairly similar. Fig. 5 presents the optimized selfconsumption rates based on realistic and ideal forecasts for a two months period. The boxplot displays the median, minimum and maximum values of daily self-consumption rates observed over this period, as well as the interquartile range. It shows a decrease of the self-consumption rates when scheduling the appliances based on realistic day-ahead forecast, compared to ideal forecast, with a median value of $\mathrm{SC}_{\%}$ going from $60.5 \%$ to $57.5 \%$.

Table 4: Comparison of $\mathrm{SC}_{\%}$ for consumption patterns optimized based on realistic and ideal forecasts of the production

\begin{tabular}{cccccc}
\hline Initial SC $\%$ & \multicolumn{2}{c}{ Optimized $\mathrm{SC}_{\%}$} & \multicolumn{2}{c}{$\mathbf{g}_{\mathrm{sc}}$} \\
\hline $\mathbf{D a y}$ & Initial & $\begin{array}{c}\text { Realistic } \\
\text { forecast }\end{array}$ & $\begin{array}{c}\text { Ideal } \\
\text { forecast }\end{array}$ & $\begin{array}{c}\text { Ideal } \\
\text { forecast }\end{array}$ & $\begin{array}{c}\text { Realistic } \\
\text { forecast }\end{array}$ \\
\hline $\mathbf{0 7 / 0 2}$ & 7 & 11 & 11 & 57 & 57 \\
$\mathbf{0 8} / \mathbf{0 2}$ & 47 & 99 & 100 & 14 & 15 \\
$\mathbf{0 9} / \mathbf{0 2}$ & 16 & 75 & 75 & 60 & 60 \\
$\mathbf{1 0} / \mathbf{0 2}$ & 57 & 72 & 36 & 69 & 125 \\
$\mathbf{1 1 / 0 2}$ & 49 & 49 & 49 & 26 & 40 \\
$\mathbf{1 2 / 0 2}$ & 9 & 26 & 26 & 189 & 189 \\
$\mathbf{1 3 / 0 2}$ & 26 & 40 & 42 & 54 & 62 \\
\hline
\end{tabular}

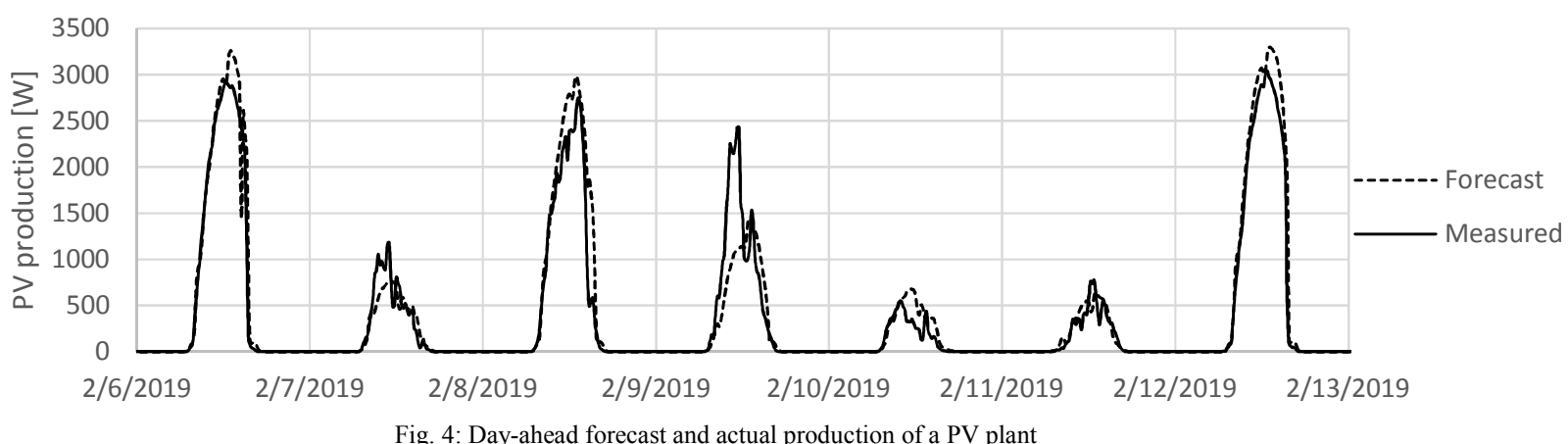

Fig. 4: Day-ahead forecast and actual production of a PV plant 


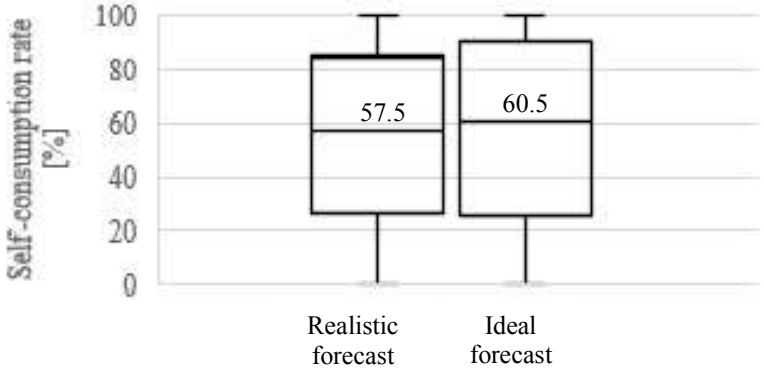

Fig. 5: boxplot of the daily SC rates over two months (median, minimum, maximum and interquartile range)

\section{B. Discussion}

The results illustrated on Fig. 5 show the importance of evaluating an energy management method based on realistic PV production forecast, in order not to over-estimate the potential of the method. Using a realistic day-ahead forecast reduces the benefit brought by the demand response method. In order to obtain better results, real time adjustments of the scheduling can be made, based on a production forecast with a shorter horizon. However, a practical implementation of real-time energy management methods brings significantly more complexity in the energy management system. It would be interesting to assess the benefits of real-time methods compared to day-ahead scheduling of the consumption. The method presented in this paper takes advantage of long-term production surplus to schedule household appliances with a long running time. It is likely that methods striving to use short term electricity surplus by loading batteries or transforming it into heat would benefit more from a real-time scheduling. Indeed, the optimal scheduling of appliances with a long operating time is only marginally affected by short-term variations in the production.

\section{CONCLUSION}

This paper presented a sensitivity analysis based on a demand response method, investigating its dependency with the prosumer load profile and with the production forecast accuracy. A method for improving the consumption pattern of a household by scheduling a set of programmable appliances is implemented. The scheduling is chosen dayahead using a genetic algorithm. Three different objective functions are proposed for the optimization: the scheduling can be chosen to maximize the self-production rate, the selfconsumption rate or to minimize the peak power exchanged with the DSO. This method was applied to nine different prosumer profiles and provides positive results in all cases. However, the improvement in the value of the chosen optimization objective vary significantly depending on the prosumer's initial consumption pattern. It is therefore advisable to assess the potential of an energy management method by applying it to a diversity of prosumer profiles, in order to take into account this variability.

The impact of PV production forecast accuracy on the results of a day-ahead scheduling of appliances highlighted in Part V shows the need to use realistic forecast data when evaluating an energy management method. With a realistic day-ahead forecast, the results of the chosen method are slightly under those obtained with an ideal forecast. Using real-time optimization based on forecast with a shorter horizon could improve the results, but would complicate significantly the energy management system. In the study presented in Part V, a lower forecast accuracy causes little decrease in $\mathrm{SC}_{\%}$.

In further work, advanced method for optimizing the consumption pattern of a household or a group of households will be developed, taking into account the control of electrical heating and energy storage systems. In this context, the need for real-time control may arise, if the impact of day-ahead forecast quality becomes significant.

The organization of prosumers into microgrids for collective self-consumption is interesting, as it reduces the impact of single prosumer profiles on the evaluation of the benefits brought by a demand response method. The association of prosumers can increase their overall flexibility and their potential for consuming their own electricity. With enough flexibility in its consumption, a microgrid could integrate a larger PV production without affecting the distribution grid stability or prompting the need to resize electricity distribution infrastructure.

\section{REFERENCES}

[1] J. I. Briano, M. J. Baez, and R. M. Morales, "PV Grid Parity Monitor - Residential Sector - 3rd issue." CREARA, Feb-2015.

[2] T. Lang, D. Ammann, and B. Girod, "Profitability in absence of subsidies: A techno-economic analysis of rooftop photovoltaic selfconsumption in residential and commercial buildings," Renew. Energy, vol. 87, pp. 77-87, Mar. 2016.

[3] Y. He and M. Petit, "Valorization of demand response for voltage control in MV distribution grids with distributed generation," in 2016 IEEE International Energy Conference (ENERGYCON), 2016, pp. 1-6.

[4] R. Luthander, J. Widén, D. Nilsson, and J. Palm, "Photovoltaic selfconsumption in buildings: A review," Appl. Energy, vol. 142, pp. 8094, Mar. 2015

[5] R. Verschae, H. Kawashima, T. Kato, and T. Matsuyama, "Coordinated energy management for inter-community imbalance minimization," Renew. Energy, vol. 87, pp. 922-935, Mar. 2016.

[6] E. Ghiani, C. Vertuccio, and F. Pilo, "Optimal sizing and management of a smart Microgrid for prevailing self-consumption," in 2015 IEEE Eindhoven PowerTech, 2015, pp. 1-6.

[7] M. Elkazaz, M. Sumner, S. Pholboon, and D. Thomas, "Microgrid Energy Management Using a Two Stage Rolling Horizon Technique for Controlling an Energy Storage System," in 2018 7th International Conference on Renewable Energy Research and Applications (ICRERA), 2018, pp. 324-329.

[8] M. Ueshima, K. Yuasa, and T. Babasaki, "Improving energy selfconsumption rate by using weather forecasts in renewable energy system for back-up power supply," in 2017 IEEE International Telecommunications Energy Conference (IN TEEC), 2017, pp. 294299.

[9] C. Stevanoni, F. Vallée, Z. D. Grève, and O. Deblecker, "Daily game theoretical management of a connected industrial microgrid," in 2017 IEEE Innovative Smart Grid Technologies - Asia (ISGT-Asia), 2017, pp. 1-5.

[10] M. Castillo-Cagigal et al., "PV self-consumption optimization with storage and Active DSM for the residential sector," Sol. Energy, vol. 85, no. 9, pp. 2338-2348, Sep. 2011.

[11] N. Pflugradt, J. Teucher, B. Platzer, and W. Schufft, "Analysing lowvoltage grids using a behaviour based load profile generator," Renew. Energy Power Qual. J., pp. 361-365, Mar. 2013.

[12] W. F. Holmgren, C. W. Hansen, and M. A. Mikofski, "pvlib python: a python package for modeling solar energy systems," J. Open Source Softw., vol. 3, no. 29, p. 884, Sep. 2018.

[13] Ministère de l'environnement, de l'énergie et de la mer, $\mathrm{JO} n^{\circ} 0109$ du 10/05/2017 | Legifrance. 2017.

[14] Ministère de l'environnement, de l'énergie et de la mer, $\mathrm{JO} n^{\circ} 0174$ du 31/07/2018 | Legifrance. 2018.

[15] F. D. Kanellos, "Real-Time Control Based on Multi-Agent Systems for the Operation of Large Ports as Prosumer Microgrids," IEEE Access, vol. 5, pp. 9439-9452, 2017. 